\title{
A CRISE DO ENSINO JURÍDICO E O PAPEL DO DOCENTE NO PROCESSO DE TRANSFORMAÇÃO DA REALIDADE SOCIAL
}

\section{THE CRISIS OF LEGAL EDUCATION AND THE ROLE OF TEACHERS IN THE PROCESS OF TRANSFORMATION OF SOCIAL REALITY}

\author{
${ }^{1}$ Ramon Rocha Santos \\ ${ }^{2}$ Carlos Pinna De Assis Junior
}

\section{RESUMO}

O presente estudo tem como objetivo analisar a crise do ensino jurídico em nosso país, identificando os principais fatores que contribuem para a situação preocupante atinente à péssima qualidade dos cursos jurídicos e apresentando soluções tendentes a minorar este grave problema. Partindo-se de uma abordagem histórica, buscar-se-á investigar o atual fenômeno de democratização do ensino e a proliferação de cursos de Direito em nosso país, com ênfase na figura do docente como agente responsável pelo atual cenário e, ao mesmo tempo agente transformador da realidade social.

Palavras-chave: Ensino jurídico, Crise, Democratização, Docente, Transformação

\begin{abstract}
The present study aims to analyze the crisis of legal education in our country, identifying the main factors that contribute to the worrying situation regards the poor quality of legal and presenting solutions aimed at alleviating this serious problem courses. Beginning with a historical approach, will seek to investigate the current phenomenon-the democratization of education and the proliferation of courses of law in our country, with emphasis on the figure of the teacher as the agent responsible for the current scenario and, while agent transforming social reality.
\end{abstract}

Keywords: Legal education, Crisis, Democratization, Teaching, Transformation

\footnotetext{
${ }^{1}$ Doutorando em Direito na Universidade Federal da Bahia, UFBA, Salvador - BA (Brasil). Professor da

Universidade Tiradentes - UNIT, Aracaju - SE (Brasil). E-mail: ramonrocha@ hotmail.com

${ }^{2}$ Graduado em Direito pela Universidade Tiradentes - UNIT, Aracaju - SE (Brasil).

E-mail: carlospinnajunior@gmail.com
} 


\section{INTRODUÇÃO}

O presente artigo se propõe a analisar criticamente a atual situação do ensino jurídico no nosso país a partir de uma compreensão histórica do fenômeno, destacando o papel do docente como agente mitigador ou mesmo transformador da realidade social.

Buscar-se-á identificar as principais causas da chamada "crise do ensino jurídico" ", notadamente marcado pela péssima qualidade dos cursos de Direito espalhados pelo país, reflexo de um outro problema não menos grave diretamente ligado a um ensino médio não menos deficitário, decorrência lógica de uma política pública de massificação do ingresso às universidades.

A consequência natural de tudo isso é a proliferação de instituições privadas de nível superior, a maioria delas sem padrões razoáveis de qualidade e desprovidas de qualquer preocupação com a formação acadêmica Sem a pretensão de analisar o chamado "macrossistema de ensino", a análise se restringirá ao ensino superior em Direito, abordando mais detidamente os fatores que contribuíram para o ocaso, destacando a figura do professor universitário como agente transformador da realidade posta, apresentando os desafios e perspectivas para a superação do problema.

\section{EVOLUÇÃO HISTÓRICA DO ENSINO JURÍDICO}

O ensino jurídico no Brasil remonta ao período imperial, a partir da sanção da Carta de Lei de 11 de agosto de 1827, de tendência liberal, que instituiu os cursos de Direito em São Paulo e Olinda.

1 GOMES, Luis Flávio. A crise (tríplice) do ensino jurídico. Disponível em 〈http://www.egov.ufsc.br/portal/sites/default/files/anexos/29134-29152-1-PB.pdf〉. Acesso em 30 jun 2015.

2 SANTOS, Anderson Clei. O ensino como um microssistema do ensino brasileiro: problemas e desafios. In: PESSOA, Flávia Moreira Guimarães (org.). Reflexões sobre a docência jurídica. Série Estudos de Metodologia. Volume 1. Aracaju: Evocati, 2013, p. 205. 
A esse respeito, vale a pena registrar a crítica contundente da ilustre professora Adélia Moreira Pessoa ${ }^{3}$ ao apontar a ausência de espírito científico e doutrinário ao referido diploma normativo, exagerado no espírito retórico e pouco objetivo.

Com o fortalecimento do positivismo, já no período republicano, temos a primeira transformação do ensino jurídico brasileiro que culminou com o fim do monopólio dos dois cursos de Direito até então existentes, permitindo-se a criação de novas faculdades de Direito, a primeira delas surgida na Bahia, em 1891.

\begin{abstract}
Com o advento da República findava o monopólio das Faculdades de São Paulo e Recife. Surgem faculdades livres, estaduais e particulares. Às duas faculdades, criadas em 1827, acrescentaram-se 14 instituições de ensino jurídico até 1930 (algumas tiveram vida efêmera). A Faculdade Livre de Direito da Bahia foi a primeira a funcionar no novo regime, tendo sido instalada em 18 de abril de 1891. No Distrito Federal surgem duas faculdades, Faculdade de Ciências Jurídicas e Sociais e a Faculdade Livre de Direito. Minas Gerais teve inaugurada oficialmente sua faculdade de Direito, em 10 de dezembro de 1892, na então capital do Estado, Ouro Preto, tendo papel de destaque em sua fundação, o então presidente de Minas, Afonso Pena. O Rio Grande do Sul instituía a Faculdade de Direito de Porto Alegre, em 1900. A Faculdade Livre de Direito do Pará foi oficialmente instalada em 31 de março de 1902 e a do Ceará surgiria em 1903, tendo ambas recebido influência da Faculdade do Recife. A do Amazonas apareceria em $1909^{4}$.
\end{abstract}

É interessante observar que a expansão indiscriminada dos cursos de Direito, um dos principais motivos apontados para a chamada crise do ensino jurídico atual, remonta ao Século XIX. Percebe-se, portanto, que o discurso liberal de expansão do ensino superior (notadamente na área jurídica) remonta ao século retrasado, forte na crença de que a regulação deveria ocorrer unicamente pela seleção natural do próprio mercado.

Com o aumento indiscriminado do número de vagas e massificação decorrente da expansão dos cursos jurídicos, começam a surgir as primeiras críticas a este modelo de ensino liberal.

\footnotetext{
3 PESSOA, Adélia Moreira Guimarães. Ensino jurídico no Brasil: da implantação à reforma universitária. In: PESSOA, Flávia Moreira Guimarães (org.). Reflexões sobre a docência jurídica. Série Estudos de Metodologia. Volume 1. Aracaju: Evocati, 2013 , p. 26.

${ }^{4}$ PESSOA, Adélia Moreira Guimarães. Ensino jurídico no Brasil: da implantação à reforma universitária. In: PESSOA, Flávia Moreira Guimarães (org.). Reflexões sobre a docência jurídica. Série Estudos de Metodologia. Volume 1. Aracaju: Evocati, 2013 , p. 39.
} 
A chamada "fábrica de bacharéis" - expressão muito utilizada na época para se referir a este fenômeno expansionista - permitiu um inevitável aumento de docentes na área jurídica desprovido de qualquer preocupação com a formação pedagógica, sendo que o "termômetro" utilizado para aferir a qualidade do professor de Direito era o sucesso profissional na respectiva área de atuação.

A partir da década de 30, com o surgimento do Estado Social, é institucionalizado definitivamente o regime universitário, com o Decreto-Lei 19.851.

No campo da educação, o período posterior a 1930 seria iniciado com a criação do Ministério da Educação e Saúde. Sua ação se fez sentir logo, através dos atos do seu primeiro titular, Francisco Campos. Em relação ao ensino superior, destacase p Dec. Lei 19.851 que dispõe sobre o ensino superior no Brasil e adota o regime universitário ${ }^{5}$.

Não foi estabelecida, entretanto, uma regulação qualitativa dos cursos de Direito, mantendo-se o modelo liberal, com base na pedagogia tradicional.

Em 1961, ano de surgimento da Lei de Diretrizes e Bases da Educação Nacional, na tentativa de solucionar o descompasso social do ensino jurídico surge o "currículo mínimo" para os cursos de Direito.

No referido modelo, era requerido um mínimo necessário para a formação jurídica dos estudantes do curso de Direito. Entretanto, em razão da ausência de controle, as regras passaram a ser novamente ditadas pelo mercado e "o currículo mínimo tornou-se, a rigor, um currículo máximo", na ilustrativa lição de Alberto Venâncio Filho ${ }^{6}$.

O golpe militar de 1964 e, sobretudo, os acordos firmados entre o MEC (Ministério da Educação e Cultura) e a USAID (United States Agency for International Development), abriram novas possibilidades de alteração na estrutura dos cursos de Direito.

Com o advento da Constituição Federal de 1988, com a introdução de diversos direitos e garantias no nosso ordenamento jurídico, abre-se espaço para transformações no ensino jurídico tradicional clássico. Era o momento de possibilidade de alteração das estruturas curriculares atrasadas.

\footnotetext{
5 PESSOA, Adélia Moreira Guimarães. Ensino jurídico no Brasil: da implantação à reforma universitária. In: PESSOA, Flávia Moreira Guimarães (org.). Reflexões sobre a docência jurídica. Série Estudos de Metodologia. Volume 1. Aracaju: Evocati, 2013 , p. 43.

6 VENÂNCIO FILHO, Alberto. Das arcadas ao bacharelismo. 2. ed. São Paulo: Perspectivas, 1982 , p. 318.
} 
Em relação aos professores, os profissionais com formação técnica minimamente requeridas típica do ensino jurídico tradicional passariam a ser substituídos por profissionais com melhor formação técnica.

A OAB, através de sua Comissão de Ensino Jurídico passa a ter papel importante neste processo, tendo como ponto culminante a Portaria $\mathrm{n}^{\mathrm{o}} 1.886 / 94$ do MEC, que regulou as diretrizes curriculares mínimas para os cursos jurídicos no Brasil.

Nos últimos anos, verifica-se um aumento considerável nos cursos de Direito. Com efeito, no ano de 2010, haviam 1.240 cursos de Direito no Brasil. Só para que se tenha uma ideia do exagero nos números, no mesmo período, todos os outros países do mundo reunidos contabilizavam apenas 1.100 cursos de Direito.

Esta massificação é apontada por muitos como um dos fatores determinantes para a crise do ensino jurídico, cuja análise será feita no capítulo seguinte.

\section{A CRISE DO ENSINO JURÍDICO}

A (má) qualidade do ensino jurídico no nosso país tem despertado a preocupação de juristas e, principalmente, educadores que tem se debruçado na análise do problema, na tentativa de identificar as causas e apontar soluções para evitar este processo de deterioração dos cursos de Direito.

Conforme se procurou demonstrar no capítulo anterior, essa crise não é recente. Desde que foram instituídos os primeiros cursos de Direito no nosso país, em 11 de agosto de 1827, que o ensino jurídico vem encontrando problemas.

Em razão da forte influência do positivismo legalista, o ensino jurídico sempre foi desenhado de forma distanciada da realidade social.

A maioria dos cursos de Direito, ainda hoje, permanecem resistentes à mudanças, impedindo o desenvolvimento de uma visão crítica. A preocupação exacerbada com a instituição de técnicas voltadas para a eficiência vem imprimindo ao Direito uma visão tecnicista e legalista, totalmente dissociada da realidade cultural e social.

Em razão deste isolamento e falta de conexão com a realidade circundante, o ensino jurídico tem se tornado cada vez mais pobre, pouco reflexivo e ultrapassado.

Os fatores que contribuem para a referida "crise" são os mais variados possíveis. 
Há quem aponte a proliferação dos cursos jurídicos e instituições privadas de ensino superior, a grande maioria sem padrões razoáveis de qualidade, como uma das principais causas para esta crise.

O abuso na utilização da aula expositiva é outro fator apontado como desencadeador da crise do ensino jurídico tradicional. De acordo com Antônio Carlos Gil ${ }^{7}$ :

\begin{abstract}
A adoção desse modelo torna problemática a aprendizagem. O professor preocupa-se em expor a matéria e negligencia a importância do interesse e da atenção do aluno. Seu discurso inclui termos que nem sempre existem na experiência dos alunos. Tantas são as ideias apresentadas que boa parte delas não é retida pelos alunos. Alguns professores falam tão rápido que muitas das ideias apresentadas não são percebidas pelos alunos. Outros falam tão baixo e de forma tão monótona que não conseguem manter a atenção dos alunos. Muitos professores ficam tão entusiasmados coma exposição a ponto de deixar de utilizar qualquer recurso audiovisual. Em suma, as aulas expositivas com frequência caracterizam-se pelo monólogo.
\end{abstract}

A ênfase no verbalismo é outro fator apontado pela doutrina que muito contribui para a atual situação vivenciada pela docência jurídica.

$\mathrm{Na}$ esteira do raciocínio de Alexandre Campos Melo ${ }^{8}$ :

O ensino de Direito no Brasil sempre se caracterizou pelo uso de aulas-conferência, técnica pedagógica consistente na transmissão de conhecimentos, pelo professor, de forma unilateral. O domínio da linguagem técnico-jurídica, a farta citação de doutrina e jurisprudência e a ausência de uma abordagem interdisciplinar são elementos que fazem parte do imaginário do que seria um "bom professor de Direito".

Assim, a consequência imediata é que o professor jurídico assume um papel de reprodutor do conhecimento, limitando-se a transmiti-lo de forma repetida e acrítica. Não se propicia, por conseguinte, um espaço para a reflexão do aluno e para o desenvolvimento de novos saberes.

Ademais, a exposição tradicional, fundamentada na verbalização, é considerada estratégia pouco eficiente. Em geral, os esforços verbais dos professores induzem o aluno a decorar a matéria, e não a compreender o seu significado e aplicabilidade a situações concretas.

Esse modelo de educação que dá ênfase ao verbalismo do professor é retratado com bastante propriedade por Paulo Freire ${ }^{9}$. É a chamada "educação bancária".

\footnotetext{
7 GIL, Antônio Carlos. Metodologia do ensino superior. São Paulo: Atlas, 2009, p. 69.

8 MELO, Alexandre Campos. Ensino jurídico no Brasil e a necessidade de reformulação de práticas pedagógicas. In: PESSOA, Flávia Moreira Guimarães (org.). Reflexões sobre a docência jurídica. Série Estudos de Metodologia. Volume 1. Aracaju: Evocati, 2013, p. 100-101.

9 FREIRE, Paulo. Pedagogia do oprimido. Rio de Janeiro: Paz e Terra, 2005, p. 65-66.
} 
Narração de conteúdos que, por isto mesmo, tendem a petrificar-se ou a fazer-se algo quase morto, sejam valores ou dimensões concretas da realidade. Narração ou dissertação que implica um sujeito - o narrador - e objetos pacientes, ouvintes - os educandos. Há uma quase enfermidade da narração. A tônica da educação é preponderantemente esta - narrar, sempre narrar. [...] Por isto mesmo é que uma das características desta educação dissertadora é a 'sonoridade' da palavra e não sua força transformadora. [...] a narração, de que o educador é o sujeito, conduz os educandos à memorização mecânica do conteúdo narrado. Mais ainda, a narração os transforma em 'vasilhas', em recipientes a serem 'enchidos' pelos educados. Quanto mais vá 'enchendo' os recipientes com seus 'depósitos', tanto melhor educador será. Quanto mais se deixem docilmente 'encher', tanto melhores educandos serão.

Contrapondo-se a este modelo de "educação bancária”, assevera Vera Barreto ${ }^{10}$ :

As pessoas são sujeitos e não objetos neste processo. Elas realizarão este esforço de aprendizagem para construir o seu saber, estimuladas por outros, mas de acordo com o que já sabem, porque o conhecimento é social.

Referido modelo de ensino privilegia o ato de repetição e memorização do conteúdo ensinado. O professor, figurativamente, por meio de aulas expositivas, deposita na cabeça do aluno conceitos a serem exigidos, posteriormente, na avaliação, quando então, aquele obtém o extrato daquilo que foi "depositado".

Evidencia-se, portanto, que o verbalismo exacerbado inibe o desenvolvimento do raciocínio jurídico e da reflexão crítica pelo aluno, criando-se uma falsa ideia de que o bom professor é aquele que exerce um amplo domínio das retórica, independentemente do grau de compreensão do que foi explanado por parte dos alunos.

Um outro fator que aponta para a falência do ensino jurídico é prática pedagógica fragmentada, que promove uma completa dissociação entre a teoria e prática, entre o conhecimento e a realidade.

10 BARReto, Vera. Paulo Freire para educadores. São Paulo: Arte \& Ciência, 1998, p. 57. 


\section{Conforme observado por Alexandre Campos Melo ${ }^{11}$ :}

[...] é necessária a edificação de um novo paradigma do ensino jurídico, pautado na interdisciplinariedade e interconectividade no estudo das disciplinas. De fato, o modelo de conhecimento fragmentado não propicia a formação integral do acadêmico, pelo contrário: torna-o refém de um paradigma científico simplificador e incapaz de estabelecer relações entre os conhecimentos teóricos e a realidade concreta e dinâmica.

[...] A ausência de integração curricular também colabora para aumentar o fosso entre ensino e realidade, na medida em que destitui os alunos da possibilidade de desenvolverem uma visão sistêmica do Direito, necessária à aplicação das redes conceituais teóricas aos diversos contextos da realidade.

As consequências deste modelo fragmentado de ensino são apresentadas de forma bastante esclarecedora por Robertônio Santos Pessoa ${ }^{12}$, para quem:

Essa desconexão disciplinar acaba por se refletir inexoravelmente na visão que os bacharéis apresentaram do direito ao término do curso. Uma visão fragmentada, desarticulada e excessivamente disciplinar, sem qualquer vislumbre de uma concepção interdisciplinar ou da existência de eixos estruturantes da teoria e da práxis jurídica. Deixa-se de propiciar aos alunos da graduação uma visão de conjunto, gerando-se, assim, cada vez mais bacharéis fragmentados, cujas cabeças, ao término do curso, funcionam como autênticos armários, onde se encontram engavetados de forma compartimentalizada as 'doutrinas' e os 'saberes' pertinentes aos mais diversos ramos jurídicos.

Não se pode deixar de levar em consideração a figura do próprio docente como possível responsável pela crise do ensino jurídico.

11 MELO, Alexandre Campos. Ensino jurídico no Brasil e a necessidade de reformulação de práticas pedagógicas. In: PESSOA, Flávia Moreira Guimarães (org.). Reflexões sobre a docência jurídica. Série Estudos de Metodologia. Volume 1. Aracaju: Evocati, 2013, p. 105-106.

12 PESSOA, Robertônio Santos. Abordagem neoconstitucional do Direito - por uma proposta pedagógica interdisciplinar e problematizante. In: OAB ConselhoFederal - $O$ futuro da universidade e os cursos de direito:

novos caminhos para a formação profissional. Brasília: $2006, \quad$ p. 102.


Com efeito, o professor que no seu sacerdócio limita-se reproduzir teorias e textos legais, recusando-se a empreender um espírito crítico reflexivo nas aulas está contribuindo decisivamente para este processo crítico. A apresentação de um arcabouço normativo, supostamente harmônico, pronto e acabado que já apresenta todas as possíveis respostas jurídicas aliada à falta de orientação contribuem decisivamente para o distanciamento entre o conhecimento e a realidade.

Inegável, portanto, que a crise do ensino jurídico está diretamente ligada à forma como o conhecimento é passado e compreendido pelos alunos, assumindo o professor um papel indispensável na tentativa de superação da crise.

Há quem chegue a falar na existência de uma tríplice crise do ensino jurídico, definida por Luiz Flávio Gomes ${ }^{13}$ como crise científico-ideológica, político-institucional e metodológica.

$\mathrm{Na}$ linha de pensamento do festejado professor:

O ensino jurídico no nosso país acha-se submetido a pelo menos três crises: (a) científico-ideológica, (b) político-institucionale (c) metodológica.

A primeira relaciona-se com o equivocado paradigma científico do qual se parte. Necessitamos na atualidade (cada vez mais) conhecer os dois ordenamentos jurídicos vigentes, o constitucional e o legal (que por sinal, com frequiência, são antagônicos). Nas faculdades, entretanto, em geral (há exceções honrosas), ensinase só metade do que devemos aprender (a perspectiva positivista legalista do Direito e dos direitos). [...] Do ponto de vista político-institucional a crise não é menos profunda. Faculdade de Direito deveria ser o lugar apropriado para o aluno aprender a pesquisar, raciocinar, compreender e, sobretudo, argumentar, redigir arrazoados etc. No entanto, está se mercantilizando vergonhosamente. Em qualquer esquina -dizem- acha-se uma delas. Exagero à parte, certo é que temos (já) quase 450 cursos em funcionamento no país. [...] A terceira crise do ensino jurídico no Brasil está relacionada com a (total e absoluta) falência do método clássico de ensino, que padece de muitas anomalias. Esse ensino vem respaldado por currículos repletos de informações, de teorias e de princípios científicos (em tese úteis e até interessantes) mas que no dia-a-dia da faculdade não são ministrados. E quando ministrados não são devidamente aprendidos (senão decorados). E o que é aprendido (decorado) não é usado (porque não se aprende fazendo - learning doing -; aprende-se para depois saber fazer).

A velha concepção, em suma, é a seguinte: primeiro adquirir conhecimentos, para depois aprender a usá-los. Primeiro a sistematização de tudo, depois a problematização. Primeiro a teoria, depois a prática. Esse método de ensino está completamente equivocado!

Aliás, a faculdade que continua nele ancorada está com os dias contados (em termos de reputação), porque está colocando na rua toneladas de bacharéis subinformados (nada ouviram sobre coisas importantes) ou super(mal) informados (ouviram falar de muitas teorias, mas pouco uso sabem fazer delas).

13 GOMES, Luiz Flávio, A crise (trípice) do ensino jurídico. http://www.egov.ufsc.br/portal/sites/default/files/anexos/29134-29152-1-PB.pdf. Acesso em 30 de junho de 2015.

Disponível em: 
O renomado professor faz referência ainda a um último problema, que diz respeito à ausência de formação pedagógica do professo, deixando transparecer que o conhecimento necessário ao desempenho profissional de advogados, juízes, promotores, ainda que titulado, não é suficiente para o desempenho adequado da docência, que requer conhecimentos pedagógicos próprios.

\begin{abstract}
Um último e delicado problema do ensino jurídico reside na precaríssima formação do professor: ser juiz, advogado ou promotor, ainda que titulado (doutor ou mestre), não significa nenhuma garantia de ser bom professor.

Quarta conclusão: bom professor hoje (especialmente em cursos de graduação ou de extensão universitária) é o que parte da definição de um problema concreto, reúne tudo quanto existe sobre ele (doutrina, jurisprudência, estatísticas etc.) e transmite esses seus conhecimentos com habilidade (que requer muito treinamento), em linguagem clara, direta, objetiva e contextualizada, direcionando-a (adequadamente) a cada público ouvinte. Além de tudo isso, ainda é fundamental administrar o controle emocional (leia-se: deve estar motivado para transmitir tudo que sabe, a um aluno que deve ser motivado para aprender $)^{14}$.
\end{abstract}

A partir da análise desta (tríplice) crise, a conclusão a que se chega é que o ensino jurídico encontra-se à beira do colapso. A preocupação assume contornos ainda maiores quando se constata que pouco ou quase nada tem sido feito para alterar esta realidade.

O modelo educacional vigente não possui qualquer sentido pedagógico, depositando- se nos docentes uma responsabilidade muito grande no processo de reversão do quadro desenhado na atualidade

\title{
4 O PAPEL DO DOCENTE NO PROCESSO DE SUPERAÇÃO DA CRISE DO ENSINO JURÍDICO
}

É através da educação que se produz o conhecimento necessário para o atingimento das condições sociais mais efetivas e desejáveis por parte de uma sociedade. Nesta toada, não se pode perder de vista a figura do professor como agente indispensável da relação ensino- aprendizagem e, por via de consequência, transformador da realidade.

Diante do atual cenário de crise que tem levado ao colapso do ensino jurídico no nosso país, o professor universitário assume um papel de relevo na tentativa de modificação da realidade social. Aos educadores são impostas novas demandas.

14 GOMES, Luiz Flávio, A crise (trípice) do ensino jurídico. Disponível em: http://www.egov.ufsc.br/portal/sites/default/files/anexos/2913429152-1-PB.pdf. Acesso em 30 de junho de 2015. 
Não restam dúvidas de que o professor de Direito influenciam decisivamente no ensino, seja com o estímulo intelectual, difundindo conhecimento, seja através do relacionamento interpessoal.

A esse respeito, vale a pena transcrever as preciosas palavras de Joseph Lowman ${ }^{15}$, para quem:

[...] a qualidade do ensino resulta da habilidade de um professor universitário em criar tanto estímulo intelectual como empatia interpessoal com os estudantes - as espécies de emoção e relacionamento que os motivam a dar o melhor de si no trabalho. As habilidades em gerar estímulos e em estabelecer relacionamento são relativamente independentes. Excelência em uma dessas duas habilidades pode assegurar ensino efetivo com alguns estudantes e em certos tipos de classes; um professor que domina as duas tem grande probabilidade de ser excepcional em atingir uma variedade de metas para todos os estudantes em qualquer ambiente. Professores capazes de promover cada um desses estados desejados impulsionam o aprendizado de seus estudantes, aumentando o nível de interesse dos estudantes pela matéria, e o esforço que despenderão para dominá-la.

O professor deve acreditar sempre na capacidade do aluno, estimulando-o e motivando-o, assumindo um papel de agente transformador da realidade social.

É o chamado professor exemplar, assim definindo por Joseph Lownan ${ }^{16}$ :

Professores exemplares, então, são aqueles que se sobressaem em uma ou ambas dessas duas dimensões do ensino efetivo, e são, pelo menos adequados em ambas. Todo professor competente deve ter pelo menos uma habilidade moderada em cada dimensão, mas há espaço considerável para variações.

A atual conjuntura do ensino jurídico passa a exigir que os professores sejam, para além de exemplares, agentes transformadores da realidade social, impondo-se aos educadores novas demandas.

Somente o professor exemplar terá sucesso na sociedade atual, não se admitindo as velhas práticas que contribuíram decisivamente para a atual situação de vulnerabilidade do ensino jurídico.

A falta de conscientização da importância da profissionalização e a resistência à capacitação são fatores que comprometem o ensino e contribuem para a crise. Poucos são os "professores exemplares" e, em número ainda mais reduzido, os que se permitem submeter a uma capacitação técnico-pedagógica.

${ }^{15}$ LOWMAN, Joseph. Dominando as técnicas de ensino. São Paulo: Atlas, 2004, p. 37-38.

16 LOWMAN, Joseph. Dominando as técnicas de ensino. São Paulo: Atlas, 2004, p. 53. 
Em contundente abordagem sobre o tema, assim se manifestou a professora Thaís Luzia Colaço ${ }^{17}$ :

[...] para agravar ainda mais a falta de conscientização da importância da profissionalização do magistério superior, não há homogeneidade nos profissionais de ensino do Direito no Brasil, pois hoje possuímos, nas universidades públicas e privadas, três grupos de professores.

No primeiro grupo, existem profissionais que se dedicam apenas ao ensino superior. Dentre eles, encontramos aqueles que trabalham em mais de uma instituição e, consequentemente, têm pouco tempo para preparar aulas, se dedicar à pesquisa, à extensão, à formação e à capacitação. Outros, normalmente vinculados a uma única instituição pública, trabalham em regime de dedicação exclusiva. Teoricamente possuem mais tempo para a preparação de aulas, para pesquisa, para extensão, para formação, para capacitação; atuam na pós-graduação e ocupam cargos administrativos. Envolvem-se mais com a instituição, com os colegas e com os alunos. Mas o grande questionamento que se faz em relação a esses professores é de que como eles conseguem ensinar o que não vivenciam com a prática diária.

O segundo grupo é formado por profissionais professores que atuam no mercado de trabalho nas diversas profissões do Direito como: advogados, procuradores, procuradores de justiça, juízes, delegados de polícia, fiscais, funcionários públicos, entre outros. Nesses casos, a docência representa uma atividade paralela, secundária em relação à atividade principal. Alguns se sentem apenas como profissionais do Direito e não profissionais da educação.

Esses profissionais professores muitas vezes lecionam em mais de uma instituição de ensino e, devido às suas diversas atividades, dispõe de pouco tempo para se dedicar à preparação das aulas, à pesquisa, à formatação, à capacitação, à participação efetiva na instituição de ensino em que trabalham. No entanto, a sua experiência profissional entusiasma "os alunos com os outros desafios e as exigências do mundo mercadológico", apresentando "a realidade para a sala de aula".

Algumas das suas aulas se resumem em comunicações de "enfadonhos relatos pessoais" e "os seus parâmetros profissionais são, portanto, os ganhos materiais". Desta forma, o fascínio pelos sinais exteriores de riqueza, associados ao sucesso e competência profissionais, se tornam mais nocivos do que a supervalorização da experiência pessoal.

Observamos, nesses casos, que os alunos de Direito são seduzidos pelo poder que seus mestres detêm, imaginando um dia imitá-los, sendo detentores da autoridade e do poder. Podemos ainda fazer uma analogia com o pensamento de Paulo Freire, quando trata da relação entre opressores e oprimidos:

Há, por outro lado, em certo momento da experiência existencial dos oprimidos, uma irresistível atração pelo opressor. Pelos seus padrões de vida. Participar destes padrões constitui uma incontida aspiração. Na sua alienação, querem, a todo custo, parecer com o opressor. Imitá-lo. Segui-lo. Isto se verifica, sobretudo, nos oprimidos de "classe média", cujo anseio é serem iguais ao "homem ilustre" da chamada classe "superior".

Mas o grande problema que se encontra é generalizado, pois a complexidade em compor os quadros docentes do ensino superior se agrava quando se observa que grande parte desse contingente de intelectuais envolvidos no magistério não possui formação e capacitação didático pedagógica.

17 COLAÇO, Thais Luzia. Aprendendo a ensinar direito o Direito. Florianópolis: OAB/SC Editora, 2006, p.17-18. 
É necessário, portanto, que o docente da área jurídica tenha consciência da necessidade constante de capacitação e a exata dimensão das competências e habilidades exigidas para o enfrentamento da situação atual, mantendo-se sempre aberto às mudanças impostas pelas vicissitudes da sociedade moderna e à constante necessidade de capacitação e aprendizado.

Torna-se necessária uma mudança de paradigma capaz de atender às demandas do processo de educação. A mudança deve partir do próprio docente, enquanto protagonista na intermediação do conhecimento.

A tarefa do docente vai muito além da transmissão de conhecimentos estanques. É preciso proporcionar ao aluno mecanismos condizentes com as atuais exigências.

O aluno deve estar preparado para lidar com as constantes mudanças da realidade. A informação, pura e simples, é útil, apenas enquanto não houver uma mudança que a torne obsoleta.

Ao docente cabe, então, colocar à disposição do processo de educação todo o seu potencial, tornando-se instrumento que permita ao aluno conviver com a realidade social.

O professor precisa estar maturado e constante processo de aprendizagem, exigindo- se ainda uma conduta proativa por parte do docente.

Deve, ainda, independentemente de previsão curricular, estimular práticas pedagógicas em seus alunos. Ações com esta contribuem para a construção do conhecimento. Eis que a relação ensino-aprendizagem deve ser recíproca.

Isto facilita o aprendizado. Ao apresentar os métodos de ensino, os alunos assimilarão não apenas como ensinar, mas já estarão aprendendo, porque perceberão que para ensinar se exige aprendizagem anterior.

Ao perceber que as técnicas de ensino são úteis, temos um efeito multiplicador na futura formação de docentes. Eis que serão estimulados pelo viés metodológico do ensino jurídico, passando a cada vez mais se interessar por técnicas de ensino. A atitude proativa do professor contribui para que o aluno, mais preparado para a carreira docente, retransmita todo esse procedimento, e assim sucessivamente, garantindo a formação de professores em tese mais preparados para o ensino jurídico.

Cabe também, ao professor a escolha de métodos educativos condizentes com essa realidade, sob pena de limitar-se a reproduzir conhecimento no fracassado modelo que 
vulnerou o sistema de ensino. Do contrário, estar-se-ia desprezando o enorme potencial do aluno, colocando-o na condição de vilão e responsável pelo insucesso do ensino jurídico.

Outro aspecto que precisa ficar claro é que o conhecimento pleno da matéria por parte do professor não garante a eficácia do trabalho pedagógico. Conforme anteriormente asseverado, a ausência formação pedagógica é, indubitavelmente, uma das principais causas da crise do ensino jurídico no Brasil.

É justamente por isso que se defende que a postura do educando professor é fundamental na superação da crise. O docente que se limita a transmitir o conteúdo está inegavelmente fadado ao insucesso.

\section{CONSIDERAÇÕES FINAIS}

É assente de dúvidas que o ensino jurídico no Brasil enfrenta uma profunda crise e precisa ser repensado.

É certo, ainda, que a referida crise não decorre de um fator único, o que impõe o reconhecimento de que a solução somente se fará possível após a superação de cada uma destas causas.

Por outro lado, por se tratar de um agente completamente envolvido no processo ensino-aprendizagem, é possível identificar na figura do professor, um papel de relevo na mitigação do problema.

A docência jurídica encontra-se contaminada com técnicas de ensino ultrapassadas, baseadas na pedagogia do oprimido e na concepção de "educação bancária", sem qualquer preocupação por parte dos professores com a aprendizagem de seus alunos.

É exatamente neste contexto que o docente assume um papel fundamental na superação da crise.

É necessária uma conscientização acerca da necessidade de constante capacitação didático-pedagógica do docente e inter-relação com outras áreas do conhecimento, sob pena de não se acompanhar a evolução da sociedade.

É bem verdade que esta mudança de paradigma não é fácil, sobretudo em uma área do conhecimento em que o tradicionalismo ainda impera.

O docente é diretamente responsável pelas práticas que desenvolve e o sucesso do trabalho desenvolvido dependerá de suas opções, de forma que este sucesso será maior, na 
medida em que desenvolva práticas condizentes com a superação da mera transmissão de conteúdos.

É preciso ainda que o professor assuma, por intermédio das práticas pedagógicas escolhidas, o papel de facilitador. O conteúdo deve ser trabalhado como instrumento apto a propiciar o desenvolvimento das competências que se espera do do aluno

É tarefa do professor estimular, constantemente, o aluno na reflexão crítica acerca dos conteúdos apresentados, de forma a instigá-lo a buscar respostas e soluções próprias.

Para além de ensinar o Direito e reproduzir os dogmas, os docentes devem se comprometer em realizar a sua tarefa com afinco e dedicação, despertando no aluno o espírito crítico e reflexivo, evitando assim a formação de meros repetidores e contribuindo para o desenvolvimento do Direito enquanto ciência

Tudo isso somente será possível se houver uma liberdade maior no processo ensino- aprendizagem, de modo a despertar no aluno o interesse pela pesquisa e, por via de consequência, a busca por suas próprias conclusões, sem qualquer limitação. Somente assim será possível superar a crise e promover as mudanças que se espera para a transformação da realidade social.

\section{REFERÊNCIAS}

ALVES, Elizete Lanzoni. A docência e a interdisciplinaridade: um desafio pedagógico. In:

COLAÇO, Thais Luzia. Aprendendo a ensinar direito o Direito. Florianópolis: OAB/SC Editora, 2006.

AZEVEDO, Plauto Faraco. Aplicação do direito e contexto social. São Paulo: Editora Revista dos Tribunais, 2000.

BAZZO, Vera Lúcia. Algumas reflexões sobre a profissionalidade docente no contexto das políticas para a educação superior. In: COLAÇO, Thais Luzia. Aprendendo a ensinar direito o Direito. Florianópolis: OAB/SC Editora, 2006.

BORGES, José Carlos. O Ensino Jurídico no Brasil. Salvador: JurisWay, 2011. BARRETO, Vera. Paulo Freire para educadores. São Paulo: Arte \& Ciência, 1998.

COLAÇO, Thais Luzia. Aprendendo a ensinar direito o Direito. Florianópolis: OAB/SC Editora, 2006.

COLAÇO, Thaís Luzia. Ensino do direito e capacitação docente. In: COLAÇO, Thais Luzia. Aprendendo a ensinar direito o Direito. Florianópolis: OAB/SC Editora, 2006. 
DEMO, P. Professor e Seu Direito de Estudar. In: NETO, Maciel (org.), Reflexões Sobre a Formação de Professores. Campinas: Papirus, 2002.

DRI, Clarissa Franzoi. Ensino Jurídico por meio da Extensão Universitária: os dilemas da indissociabilidade. In: COLAÇO, Thais Luzia. Aprendendo a ensinar direito o Direito. Florianópolis: OAB/SC Editora, 2006.

ESTRELA, M. T. A Investigação como Estratégia de Formação Contínua de Professores: Reflexão Sobre Uma Experiência. In: NETO, Maciel (org.), Reflexões Sobre a Formação de Professores. Campinas: Papirus, 2002.

FARIA, José Eduardo. Sociologia Jurídica: crise do Direito e práxis política. Rio de Janeiro: Forense, 1984.

FONSECA, Hermes da. Em defesa da "perfumaria": por uma história do direito com cheiro e gosto. In: COLAÇO, Thais Luzia. Aprendendo a ensinar direito o Direito. Florianópolis: $\mathrm{OAB} / \mathrm{SC}$ Editora, 2006.

FREIRE, Paulo. Pedagogia da autonomia. Rio de Janeiro: Paz e Terra, 1996. FREIRE, Paulo. Pedagogia do oprimido. Rio de Janeiro: Paz e Terra, 2005. GIL, Antônio Carlos. Metodologia do ensino superior. São Paulo: Atlas, 2009.

GOMES, Luiz Flávio. A crise (tríplice) do ensino jurídico. Disponível em http://www.egov.ufsc.br/portal/sites/default/files/anexos/29134-29152-1-PB.pdf. Acesso em 30 de junho de 2015.

GONZÁLEZ, Elsa Inés Rumak de. Avaliação da aprendizagem. In: COLAÇO, Thais Luzia. Aprendendo a ensinar direito o Direito. Florianópolis: OAB/SC Editora, 2006.

JACINTHO, Jussara Maria Moreno. Dignidade Humana - Princípio Constitucional. Paraná: Juruá, 2009.

LOWMAN, Joseph. Dominando as técnicas de ensino. São Paulo: Atlas, 2004.

MARQUES, Fabiano Lepre. Ensino Jurídico: o embate entre a formação docente e o pacto da mediocridade. In: GARCIA, Maria (org.). Revista de Direito Educacional. São Paulo: Revista dos Tribunais, 2011.

MONDARDO, Dilsa. Metodologia do Ensino do Direito: memórias de um cronópio. In:

COLAÇO, Thais Luzia. Aprendendo a ensinar direito o Direito. Florianópolis: OAB/SC Editora, 2006.

MELO, Alexandre Campos. Ensino jurídico no Brasil e a necessidade de reformulação de práticas pedagógicas. In: PESSOA, Flávia Moreira Guimarães (org.). Reflexões sobre a docência jurídica. Série Estudos de Metodologia. Volume 1. Aracaju: Evocati, 2013. 
MONDARDO, Dilsa. Metodologia do Ensino do Direito: memórias de um cronópio. In: COLAÇO, Thais Luzia. Aprendendo a ensinar direito o Direito. Florianópolis: OAB/SC Editora, 2006.

MURICY, Marília. Aprendendo direito o Direito. In OAB Ensino Jurídico - O futuro da universidade e os cursos de direito: novos caminhos para a formação profissional. Brasília: OAB, Conselho Federal, 2006.

PESSOA, Adélia Moreira Guimarães. Ensino jurídico no Brasil: da implantação à reforma universitária. In: PESSOA, Flávia Moreira Guimarães (org.). Reflexões sobre a docência jurídica. Série Estudos de Metodologia. Volume 1. Aracaju: Evocati, 2013.

PESSOA, Flávia Moreira Guimarães (org.). Reflexões sobre a docência jurídica. Série Estudos de Metodologia. Volume 1. Aracaju: Evocati, 2013.

PESSOA, Robertônio Santos. Abordagem neoconstitucional do Direito - por uma proposta pedagógica interdisciplinar e problematizante. In: OAB Ensino Jurídico - O futuro da universidade e os cursos de direito: novos caminhos para a formação profissional. Brasilia: OAB, Conselho Federal, 2006.

PIRES, Patrícia da Silva. A discussão enquanto técnica de ensino no direito que efetiva o construtivismo no processo ensino-aprendizagem. In: COLAÇO, Thais Luzia. Aprendendo a ensinar direito o Direito. Florianópolis: OAB/SC Editora, 2006.

RABAÇA, Sandra V. C. O direito de aprender vs. o dever de ensinar. In: GARCIA, Maria (org.). Revista de Direito Educacional. São Paulo: Revista dos Tribunais, 2011.

SANTOS, Anderson Clei. O ensino como um microssistema do ensino brasileiro: problemas e desafios. In: PESSOA, Flávia Moreira Guimarães (org.). Reflexões sobre a docência jurídica. Série Estudos de Metodologia. Volume 1. Aracaju: Evocati, 2013

SIQUEIRA, Julio Pinheiro Faro Homem de. Ensino Jurídico: em busca do habitus de transformação. In: GARCIA, Maria (org.). Revista de Direito Educacional. São Paulo: Revista dos Tribunais, 2011.

VENÂNCIO FILHO, Alberto. Das arcadas ao bacharelismo. 2. ed. São Paulo: Perspectivas, 1982.

WOLKMER, Antônio Carlos. História do Direito no Brasil. 3. ed. Rio de Janeiro: Forense, 2003.

WOLKMER, Antônio Carlos. Introdução ao pensamento jurídico crítico. 5. ed. São Paulo: Saraiva, 2006. 